\title{
Chapter 4 \\ How to Implement Life Cycle Management in Business?
}

\section{Eskinder Demisse Gemechu, Guido Sonnemann, Arne Remmen, Jeppe Frydendal, and Allan Astrup Jensen}

\begin{abstract}
This chapter discusses how business can implement life cycle sustainability assessment into their management strategies. Life cycle management is a management approach that provides business a systematic way of managing their sustainability issues. The PDCA (Plan, Do, Check and Act) cycle is one of the quality management tools that can be used by companies to implement life cycle management initiatives in order to improve their sustainability performance. The relevance of the PDCA cycle is discussed to ensure a continuous performance improvement by setting and implementing a well-defined plan, checking whether the ambition goals are achieved or any adjustment actions are needed to continue the evaluation process.
\end{abstract}

Keywords Life cycle assessment $\bullet$ Life cycle management $\bullet$ Life cycle sustainability assessment $\bullet$ PDCA cycle (plan, do, check, act)

E.D. Gemechu $(\bowtie) \bullet$ G. Sonnemann

University of Bordeaux, ISM, UMR 5255, 33400 Talence, France

CNRS, ISM, UMR 5255, 33400 Talence, France

e-mail: eskinder.gemechu@u-bordeaux.fr
A. Remmen
Aalborg University, Aalborg, Denmark
J. Frydendal
Ecolabelling Denmark
Danish Standards Foundation

\section{A.A. Jensen}

Nordic Institute of Product Sustainability, Environmental

Chemistry and Toxicology (NIPSECT), Copenhagen/Frederiksberg, Denmark

G. Sonnemann, M. Margni (eds.), Life Cycle Management,

LCA Compendium - The Complete World of Life Cycle Assessment,

DOI 10.1007/978-94-017-7221-1_4 


\section{Introduction}

Global companies recently have shown an increasing interest in being engaged in sustainability initiatives and integrating it to their business management strategies through broadening their accountability beyond economic performance to include social and environmental aspects (Labuschagne et al. 2005). There are a number of driving forces behind their engagement: government regulation and intervention, stakeholder pressures, economic profit, globalization, business concern for society and the environment, technological advancement, social activism and so on (Estein and Buhovac 2010). The direct intervention of governments at regional, national or international level is one of the drivers. Governments are highly encouraging companies to improve their environmental and social performance while maintaining their economic benefits (Simpson et al. 2004). A number of legislation and regulatory initiatives have been established to promote technological advancement (Carraro and Galeotti 1997).

The development of methodological tools, databases, guidelines and procedures are being supported by governments so as to promote sustainability practices in businesses that can contribute to the transition towards a more sustainable economy. Some examples from the European Union (EU) are the EC directive on disclosure of non-financial and diversity information by large companies, which requires companies with more than 500 employees to include information about their environmental and social performance in their annual reports (EC 2014), the EC's strategy on corporate social responsibility (CSR), which encourages companies to have in place a system that integrates consumer concerns, environmental, ethical human rights and other social aspects into their business operations and core strategy with close collaboration with their partners (EC 2011). A number of national governments have also established policy initiatives to promote sustainability practice by businesses.

Besides governments' interventions, there are also other driving factors for companies' commitments to sustainability initiatives. One is the change in consumers' behavior towards sustainable consumption patterns. Consumers have become more concerned about the environmental pressure associated with products for their consumptions. They are showing commitments to buy products with relatively less impacts and they would like to be linked with companies that are environmentally and socially responsible (Perrini et al. 2010; Cherian and Jacob 2012). Companies that place sustainability initiatives into their business strategies are attracting more consumers and at the end making more profits. This phenomenon could stimulate and may lead companies that are not active in sustainability practice to be engaged so as to improve their competitiveness (Ginsburg and Bloom 2004; Lacy et al. 2010).

Corporate sustainability reporting (CSR) initiatives are also serving as an internal and external driver for companies' sustainability initiatives. They encourage employees and stakeholders to be engaged in sustainable business practices at the same time they could also increase competition and threats within and across industries (Porter and Kramer 2006). Economic globalization, which is characterized by its global, liberal and open economy (Dinda 2004), technological advancement that reduces material intensity and pollutions, social activism that creates awareness about the environmental and social pressure and force governments to set a 
regulation (Ginsburg and Bloom 2004) are also among the drivers that brought sustainability innovation into business context.

Sustainability is becoming an agenda for most business nowadays, but how to implement and integrate it with other strategies remains challenging. Life cycle management (LCM) is an approach that can be used by business with the aim to operationalize their sustainability initiatives: to have better environmental, economic and social performance simultaneously. This chapter, therefore, discusses the way how business can implement LCM into their management strategies.

\section{Implementation of Life Cycle Sustainability Management}

LCM is a management approach that provides business a systematic way of managing their sustainability issues. The PDCA (Plan, Do, Check and Act) cycle is one of the quality management tools that can be used by companies to implement LCM initiatives in order to improve their sustainability performance. This section introduces the PDCA cycle and discusses in detail its relevance to successfully implement LCM in any business.

The PDCA cycle, for Plan, Do, Check and Act, which is also known as the Deming cycle, was first proposed by Walter A. Shewhart (Shewhart 2011) in the 1950s and further conceptualized by W. Edward Deming (Deming 1952) to analyze and measure business processes and identify the main causes that affect products quality from customer requirements. The PDCA cycle has its root in scientific methods that have evolved for more than 400 years (Moen and Norman 2006). The cycle is a systematic series of steps and continuous feedback loop in which managers are able to identify and take the required measure to change the parts of the process that need improvement (Sokovic et al. 2010).

The PDCA cycle is an iterative process of a four-step management method that can be applied by any business with an ambition of continuous processes and products performance improvement Fig. 4.1, Table 4.1. The "Plan" step comprises different activities and identifies the main goal and purpose of the assessment and

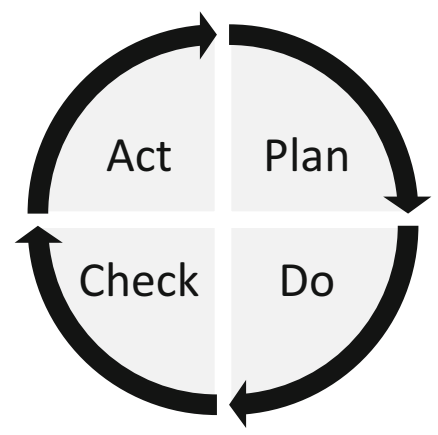

Fig. 4.1 Phases of the step-by-step approach 
Table 4.1 LCM relevance of each stages of the PDCA cycle (Remmen et al. 2007)

\begin{tabular}{|c|c|}
\hline $\begin{array}{l}\text { PDCA } \\
\text { cycle phases }\end{array}$ & LCM relevance \\
\hline \multirow[t]{4}{*}{ Plan } & Set policies - set goals and determine the ambition level \\
\hline & Organize - get engagement and participation \\
\hline & Survey - overview of where the organization is and wants to be \\
\hline & $\begin{array}{l}\text { Set goals - select areas where the efforts will be directed, determine goals and } \\
\text { make an action plan }\end{array}$ \\
\hline \multirow[t]{2}{*}{ Do } & Make environmental and social improvements - put the plan into action \\
\hline & Report - document the efforts and their results \\
\hline Check & $\begin{array}{l}\text { Evaluate and revise - evaluate the experience and revise policies and } \\
\text { organizational structures as needed }\end{array}$ \\
\hline Act & Take it to the next level - set up new goals and actions, more detailed studies, etc. \\
\hline
\end{tabular}

establishes the processes that are required to deliver the outcome. The "Do" step is a process of implementing the plan through performing a process to make the target output product. It also involves activities such as collecting and preparing data inputs to the next steps. The third stage of the PDCA cycle is the "Check" step. In this stage, the main results from the "DO" step are analyzed whether or not they meet the expected outcome set in the "Plan" step. The main factors that affect the performance of the product are identified and possible improvement solutions are suggested. The comprehensiveness of the plan to allow a proper execution of the product is checked in this step. The final stage is the "Act" step. The action is based on the output results from the "Check" stage. If the results from the "Check" reveal that the established new plan allows for an improved performance, then the action will be how the company sustains the improved performance as a new standard. On the other hand, if the plan fails to ensure an improvement, then the existing standard will remain in place. In both cases, the "Act" step closes the first cycle and continues the process by incorporating the knowledge accumulated during the entire process to be used to set a new goal, adjust the method used and so on.

LCM is a dynamic management process. Hence it considers the PDCA cycle approach among other management tools that enable a continuous business improvement over time and satisfy employees, customers and other stakeholders (Remmen et al. 2007). The PDCA cycle provides an organization with a systematic approach to management along the product life cycle. The recommendations of the PDCA cycle to the LCM are backed by the ISO management system standards for environment (ISO 2004) and quality (ISO 2008). The relevance of each PDCA element to the context of LCM is discussed in this section.

\subsection{Plan}

The PLAN step identifies the current existing level of sustainability ambition of the companies and ensures whether they have the required resources. This step generally covers the following areas: police setting (determining the level of business's 
ambitions), organize (get engagement and participation), survey and research (identify key environmental and social impacts and opportunities and decide what the business wants to be and where it would like to go) and finally goal setting (select an area/s where the efforts will be directed, determine goals and make an action plan).

\subsubsection{Policy Setting}

To consider LCM among the key success factors through all levels of any organization, it needs to be a part of the organization's policy. Therefore, it should possess the basic characteristics of an organization's policies. These are, for example: the policy has to be well known and also well understood by all stakeholders that are directly or indirectly affected from its implementation, it should be stable and not subjected to change frequently, it should be consistent with the company's organizational structure at all levels, it has to be formulated within the context of company's objectives, and more importantly, it has to be goal-based and visionary with a long-range focus, while also being realistic and concrete, grounded by its ambition level. Setting goals according to the levels of ambition ensures conformity between policy and actions. There are different levels of sustainability ambitions, just to cite a few (Table 4.2):

- Internal readiness and commitment to continuous sustainability improvements. This level signifies awareness that environmental and social improvements can be made using management frameworks such as ISO 9001 ((ISO 2008), ISO 14001(ISO 2004) and/or corporate social responsibility (CSR) (McWilliams and Siegel 2001), and that a commitment to improvements of product performance is the first step towards LCM.

- Life cycle sustainability performance improvement of products. This includes a safe and resource efficient process, product or system that provide better service to customers while reducing environmental and social impacts. This can be addressed through broadening companies' system boundaries beyond their manufacturing level, by including the full supply chain from raw materials selection and acquisition, use of product, distribution and end-of-life - based on a screening of the product's performance.

- Reduce climate change impact and be energy efficient by using low-carbon and renewable energy sources.

- Maximize the social benefits by engaging a wide range of stakeholders and also respect the rights of the social community whom the company works with.

- Create competitive advantages and maximize economic benefits from promoting products with better environmental and social profile.

Establishing such ambition levels can help an organization to understand where to begin the sustainability initiative. Depending on its past sustainability practices and current challenges, an organization can begin with a certain level of ambitions and goes to relatively high level once it acquires knowledge and familiarity on how to make its plan into action successfully. 
Table 4.2 Sustainability ambitions - examples from global leading companies

\begin{tabular}{|c|c|}
\hline Company & Sustainability ambitions \\
\hline \multirow{4}{*}{$\begin{array}{l}\text { SONY } \\
(2015)\end{array}$} & Curbing climate change - zero emissions of greenhouse gases by 2050 \\
\hline & Conserving resources - maximize the use of recycled plastic and other materials \\
\hline & $\begin{array}{l}\text { Controlling chemical substances - strict control over chemicals in raw materials } \\
\text { and parts worldwide }\end{array}$ \\
\hline & $\begin{array}{l}\text { Promoting biodiversity - protect biodiversity, both through its business } \\
\text { activities and through conservation }\end{array}$ \\
\hline \multirow{10}{*}{$\begin{array}{l}\text { BASF } \\
(2015)\end{array}$} & Improve the energy efficiency in production process by $35 \%$ \\
\hline & Reduce greenhouse gas emissions per metric ton sales product by $40 \%$ \\
\hline & $\begin{array}{l}\text { Reduce the emissions of organic substances and nitrogen to water by } 80 \% \text { and } \\
\text { heavy metals by } 60 \%\end{array}$ \\
\hline & Reduce the withdrawal of drinking water for production by $50 \%$ \\
\hline & $\begin{array}{l}100 \% \text { introduction of sustainable water management at production sites in } \\
\text { water stress areas }\end{array}$ \\
\hline & Reduce emissions of air pollutant by $80 \%$ \\
\hline & Safety, security and healthy \\
\hline & Reduce transportation accidents during shipments \\
\hline & Minimize workers lost-time injuries \\
\hline & Assess the risk of products sold by BASF worldwide \\
\hline \multirow[t]{8}{*}{$3 \mathrm{M}(2014)$} & Manage their environmental footprint \\
\hline & $\begin{array}{l}\text { Provide solutions that address both environmental and social challenges for the } \\
\text { consumers and society }\end{array}$ \\
\hline & $\begin{array}{l}\text { Assure the safety of their product for the intended use through assessing their } \\
\text { entire life cycle }\end{array}$ \\
\hline & $\begin{array}{l}\text { Appropriate management of any } 3 \mathrm{M} \text { health and safety issues that may impact } \\
\text { customers, neighbors and the public }\end{array}$ \\
\hline & Maintain a safe and healthy workplace \\
\hline & Satisfy customers through providing superior quality and value \\
\hline & Support the local community where $3 \mathrm{M}$ employees live and work \\
\hline & Provide an attractive return for our investors \\
\hline
\end{tabular}

In whatsoever ambition level is set in the sustainability policy, it should provide a clearly defined and well-grounded strategies and objectives that can ensure environmental, social and economic improvements in all relevant stages of a product profile. The product profile should include impact assessment throughout the product's life cycle, from cradle to grave, taking into account interests from different stakeholders. The product profile should also answer questions such as: Where is the position of the organization compared to its important competitors? Whether the organization has relevant supply chain information on input parts and raw materials? Whether the product provides the demanded environmental quality and social concerns by the consumers and other interested parties? Whether the organization has the necessary resources to achieve its goals?

When the policy has been set, the next steps are to organize the effort and set up specific targets. 


\subsubsection{Establish a Team for Life Cycle Management Initiatives}

LCM has to be part of an organization management processes in which it involves the participation of different parts of the organization and also different actors in the product chain when relevant. LCM initiative can be organized in a coordination group or team. The responsibility within a coordination group should lie with a team leader, who is responsible for ensuring that the group functions, meetings are arranged, minutes are taken, etc. The members of the coordination group should be selected so that all relevant departments or functions are represented, including top management, product development, production, product distribution, sales, marketing, and purchasing.

One possible option could be establishing a cross-functional team. It is a team made up of individuals from different departments within an organization. They should be not only environmental expertise, but from different backgrounds with different expertise. Cross-functional team for the implementation of LCM could be composed of members from relevant departments such as product development, production and distribution, sustainability and environment, finance and procurement, etc. Some team members may be engaged in full-time bases in order to secure continuous improvement of the environmental performance until the targets are achieved and they may return to their routine roles once the time frame is over. Other members could act as an ad hoc team in order to implement specific tasks, which could be, for example, a supplier evaluation scheme with the involvement of people from purchasing, product development and marketing. For small- or medium-sized (SMEs) organizations a single but permanent cross-functional team might be the best solution, but it depends on the specific structure and culture of the organization. Whether the cross-functional team last long or short, its members should maintain a strong link to their major responsibilities in their main department as well as maintain good relations with their managers. Although it is important to establish a cross-functional team in order to successfully implement LCM into business practice, it faces some challenges such as priority due to several responsibilities, lack of motivation due to additional tasks and others.

The establishment of a cross-functional team is a key to place LCM into action. A number of factors are crucial to successful cross-functional teams (McDonough III 2000). Setting clear and well-defined goals offer several benefits to the team members. They provide a common frame of reference, which at the end results in facilitating the team cooperation and organize the tasks. Empowerment in cross-functional team is another success factor. Allowing individual team members a decision-making responsibility help them to be more committed to the project and strive to meet the target goals. It also increases their satisfaction of being a part of the team members. Supports from senior management, such as demonstrating team commitments, providing help to overcome challenges and encouraging team members can also have a direct effect on the performance of the cross-functional team. Another key success factor is creating cross-functional team of interested people (McDonough III 2000). 
Experience with LCM and other management systems shows the value of having interested, enthusiastic people at all levels of the organization.

In general, successful implementation of LCM framework in an organization requires a proper allocation of human and other relevant resources, assignment of responsibilities and accountabilities based on each team member's role for the different tasks, building expertise based on practical experience as well as procedures and instruction to ensure that activities are running properly (Remmen et al. 2007).

\subsubsection{Review the Sustainability Status and Set Objectives and Targets}

LCM tries to implement life cycle sustainability assessment (LCSA) (UNEP 2011) into a real world decision-making process by applying a life cycle management concept with the aim of maximizing both the social, environmental and economic aspects of individual organization along its products lines (Finkbeiner 2011). Therefore, reviewing the organization's products is an important step to identify when and how to start the LCM process. The review helps to have an overview on the sustainability status of the organization and also where it wants to go for. The review process mainly covers gathering information associated with a product life cycle, market situation and external stakeholders. Information about important suppliers, business associations, authorities, retailers, research institutions, etc. needs to be included so that important aspects are covered.

Many companies already possess information on the impacts of their production processes and operations, but are uncertain of how to expand their understanding to the product life cycle and to think in terms of products rather than processes in order to identify material flows through the entire product life cycle. This would include impacts associated with suppliers, purchased materials or components, storage and distribution, use of the product and waste streams.

Important aspects that need to be reviewed are summarized in Table 4.3. They are categorized into aspects for environmental and social impacts, for market or commercial conditions and for stakeholders. Aspects for environmental and social impacts include understanding of impacts associated with the company's processes or products. The aspects should not be limited to the organization's territory, rather they have to go beyond the facility boundary to include the whole supply chain, both internal and external stakeholders. ISO 14031 - environmental management which is an environmental performance evaluation standard and guideline (ISO 2013) can be applied to asses companies in evaluating their performance against their policy, objectives, targets and other criteria associated with their products. It can also be adapted to be applied to address other management aspects, e.g. quality or health and safety, and from a sustainability perspective economic and social aspects as well. For companies engaged in sustainability actions, the information may be already available in their corporate and environmental reports. In general, this information is presented in terms of the production process, rather than the single product. 
Table 4.3 Aspects of a survey (Remmen et al. 2007)

\begin{tabular}{|c|c|}
\hline Areas of concern & Aspects to be reviewed \\
\hline \multirow[t]{3}{*}{$\begin{array}{l}\text { Environmental and } \\
\text { social impacts }\end{array}$} & $\begin{array}{l}\text { Life cycle stages - where are the most important environmental and } \\
\text { social impacts? }\end{array}$ \\
\hline & $\begin{array}{l}\text { Technology - is there a new technology available or being developed that } \\
\text { can reduce the impacts? }\end{array}$ \\
\hline & Do the competitors have the same impacts and how do they address them? \\
\hline \multirow{3}{*}{$\begin{array}{l}\text { Market/commercial } \\
\text { conditions }\end{array}$} & Supply - what are the product profile's characteristics? \\
\hline & $\begin{array}{l}\text { Demand - how important is the social and environmental awareness of } \\
\text { consumers and customers? }\end{array}$ \\
\hline & $\begin{array}{l}\text { Value - what advantages are achieved by adding positive environmental } \\
\text { and social characteristics as an extra product quality? }\end{array}$ \\
\hline \multirow[t]{5}{*}{ Stakeholders } & $\begin{array}{l}\text { Product chain actors - are suppliers, retailers or others interested in } \\
\text { collaboration on environmental and social initiatives? }\end{array}$ \\
\hline & Authorities - what are the demands of authorities? \\
\hline & $\begin{array}{l}\text { Within sector - what are competitors doing? Codes of conduct within the } \\
\text { trade? }\end{array}$ \\
\hline & $\begin{array}{l}\text { Which is the main pressure group, and what are their main concerns and } \\
\text { priorities? }\end{array}$ \\
\hline & What are the main concerns and demands of consumers in export markets? \\
\hline
\end{tabular}

In addition to information on environmental and social impacts of their products or processes, a better understanding is necessary of both internal and external stakeholders, the current market conditions and the future opportunities linked with sustainability achievements. Discussion with all relevant stakeholders helps to get information on the legal and other requirements including environmental and social concerns. In addition, such discussion is also important when setting up objectives and targets. Goals to improve products' environmental and social performance will also have an effect on customers' expectations and responses.

Once the status overview is performed, then the next step will be to set objectives and targets. The criteria to select possible areas of product improvement are based on the responses from the questions listed in the survey. In some cases, the social and environmental problems identified by an organization may be solved by another's efforts, for example, the invention of a new technology or a supplier phasing out harmful substances due to pressure from other stakeholders. Therefore, the decision on prioritizing areas of concern for LCM initiatives is based on the finding from research on the current situation and knowledge. The following aspects are usually considered in the decision process (Remmen et al. 2007):

- Areas of considerable environmental and social impacts along the products' life cycle (Relevance). Impacts occurred within the organization facility may be easily identified. But a holistic approach may be required to identify potential areas of environmental and social problems along the supply chain.

- Areas for possible environmental and social improvements (Potential). An organization can have several opportunities for improvement, and therefore 
chooses different initiatives for improvement and also to involve all the relevant departments.

- Areas where the organization can make a tangible differences (Influences). High relevance and high influence could yield high potential for real improvements.

In the objectives and goal setting, different initiatives should be established and for each initiative a corresponding action plan that explicitly states the goals, main responsibilities and the time frame needs to be defined so that plans and initiatives are clear both for the management and employees.

\subsection{Do}

\subsubsection{Put the Plan into Practice}

In the first stage of the PDCA cycle, the layout of an implementation of LCM initiatives has been established. The LCM is in place as a part of the strategic policy of an organization, teams that are responsible to carry out the initiatives are formed, the environmental and social impacts associated with the product's life cycle are specified, areas for possible improvements are identified, the goals and objectives are set. These are the preparatory processes under the "Plan" step. Planning is an important stage, but implementation is vital, as practical results create credibility, enthusiasm and active support for a product initiative. By considering the entire life cycle of a product, a number of possible improvements can be identified, for example, reducing the total environmental burden by increasing the use of paper in the office with high recycle content, increasing the use of renewable energy sources, reducing water consumption and wastewater discharge in the production process or dematerializing a product recycle content (UNEP/SETAC 2013). For all possible improvements, corresponding goals are important. Then what comes next is to place them in practice, which is the "Do" step.

In addition to performing the possible improvements in the products life cycle, the step also includes new challenges to tackle, which might include addressing new or potential issues. Environmental regulations are becoming tightened and companies need to be ready for any regulation changes, so they can adapt their goals and action plans. The company could implement life cycle thinking to engage a redesign of a product to meet the requirements of the legislation, including easier recycling, simple dis-assembly, new materials selection, etc.

For the sake of securing a continuous sustainability improvements of the product, written procedures or instructions should be established. The procedures or instructions explain methods of operation to be followed, which guarantee the continuity of the performance improvements especially when people change jobs or new staffs are hired.

Existing practices and the view of key persons have to be taken into account, in order to make the procedures work and to be part of the daily practice. The procedures should be established to support activities that are agreed to be 'standard' in the organization. 


\subsubsection{Communicating the Life Cycle Management Initiatives Efforts and Results}

The results of the initiatives, which are the outcome of an organization's commitment, need to be documented and also communicated to stakeholders and other interested parties. An official report that communicates relevant information with regard to the organization's sustainability ambitions, its managements practices in making their goals and strategies to happen and their overall contribution towards economic, environmental and social performance improvement is very crucial. Reports on initiatives can be used as a marketing tool as it demonstrates to customers, suppliers and other stakeholders how the organization is engaged in sustainability management, which in turn provides credibility, confidence and trust. The report can also serve as an internal communication tool for setting new targets, performance evaluation and re-defining strategies.

There is no mandatory format for reporting on sustainability initiatives. However, an organization can adopt different sustainability reporting frameworks to its context depending on its ambition level, for example, the Sustainability Reporting Framework established by the Global Reporting Initiative (GRI) (GRI 2013), Corporate Sustainability Reporting (McWilliams and Siegel 2001), etc. It is advantageous for an organization to have some insight into the type of environmental and social impacts that the stakeholders prioritize, so that communication can be tailored to meet these demands.

The report can cover several issues that are addressed in the LCM practice, it may include, but is not limited to (Remmen et al. 2007):

- Trends of resources consumption such as energy, water, fossil fuels and other resources

- Resources consumption reduction achievement after the introduction of LCM initiatives

- Achievement on increasing the recycle content of input raw materials in the production process

- Any effort made to reduce environmental impacts associated with distribution and transportation

- Information about the amount of solid waste production, wastewater discharges and emissions generation

- Resources supply risk and also opportunities due to geopolitical, social, relational, and other environmental factors such as climate change

- Any initiative towards increasing the social benefits of the local community, employees and other stakeholders.

Results may also be made visible by calculating key figures, for example, energy consumption during production of the product. The key figures and the practical results of the initiatives can be made public via, for instance, a leaflet, an eco-label or an environmental product declaration. Internal as well as external communications are necessary precondition for achieving the benefits of LCM initiatives. 


\subsection{Check}

Once an organization evaluates its sustainability position and sets ambition goals to move forward to an improved performance, once it initiates a plan to achieve its targeted goals and once it performs a LCM practice and finally reports the outcomes from the implementation, then the next step is to evaluate and revise its achievements and learn from its mistakes. The latter is the "Check" step of the PDCA cycle. In this stage, the effectiveness of the proposed solutions is measured. Depending on the success of the LCM initiative, once the areas of improvement are identified and the general scope of the main project are evaluated, it may be possible to incorporate the improvements by repeating the "Do" step.

The types of questions one might ask at this phase would include (Remmen et al. 2007):

- What went well? And what did not?

- Which risks were identified?

- What preventive actions should be taken?

- Were the goals met?

- How can the effort be improved?

- Should more employees be involved in the initiative?

- Should the efforts be focused in a different direction?

- Were the appropriate means and methods applied?

- What was the influence on sales and customer demands?

- Should more external stakeholders be involved?

- Should the level of ambition be raised?

This evaluation may be conducted once a year and it can provide a platform for an adjustment of an organization's policy. Based on the evaluation results, the organization may decide to continue with the same sustainability objectives and goals or even set a higher ambition level that comprises more extensive environmental and social commitments.

A step-by-step approach of the LCM ensures interaction between knowledge acquired about the social and environmental impacts of a product throughout its life cycle and the possible implementation of product-oriented sustainability performance improvements. The "Check" step of the PDCA cycle evaluates this interaction and also involves the measurement, monitoring and evaluation of products and services as well as of the management system itself. Important elements of the "Check" step are (Remmen et al. 2007):

- Monitoring the performance of the processes and products in view of the defined objectives and targets with the support of indicators

- Feedback and criticism from customers and other parties are an important information source for organizations to improve products as well as the product development process

- Establishing preventive and corrective actions for potential and actual nonconformities with requirements 
- Conducting internal audits to determine and provide information to management on whether LCM conforms to plans has been properly implemented as well as to identify improvement options.

Once the "Check" stage of the cycle is performed, the next step will be followed.

\subsection{Act}

Answers for the questions raised in the "Check" stages determine the possible actions in the "Act" stages of the PDCA cycle. If the target is met, then a new target for further sustainability improvement will be established or if the objectives are over ambitious and do not consider the potential of the company's resources, then a new target with less ambition level could be set. Therefore, the "Act" stage in any case ends the previous cycle and begins a new cycle with a new target. Whether the LCM initiatives were successful or not, the annual cycle needs to be accompanied with a top management review and setting directions (ISO 2004; Remmen et al. 2007). The top management review basically addresses if there is any need to change or modify the policies, objectives and other elements of the system in the light of audits, evaluations, changing circumstances provides management with the opportunity to continuously improve the organization's and its products' performance (Fig. 4.2).

Through the experience from the first round of improvements, an enterprise has likely identified areas for further investigations or initiatives.

If an organization's customers request documentation on the impacts of a product then a simple environmental assessment is appropriate. If it becomes evident

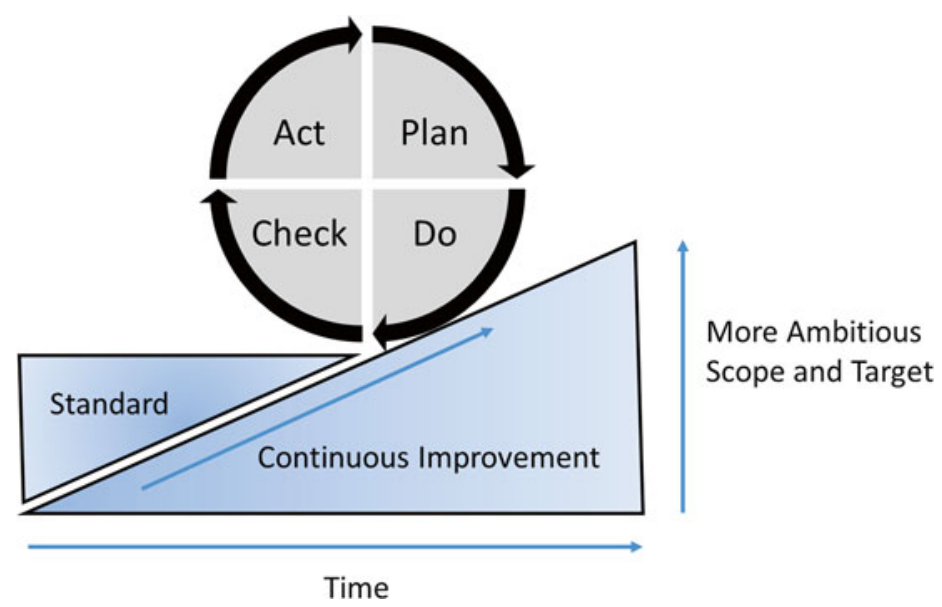

Fig. 4.2 PDCA cycle - a continuous learning and improvement process 
that there are significant environmental impacts in the use stage of a product, then an investigation of consumers' desires and demands would be an obvious departure point of further consideration. If an enterprise uses chemicals or materials, which are on the list of undesirable substances, it would be sensible to begin phasing them out.

On the basis of experience, the initial area and goal(s) are redefined and a new round of efforts begins with plans, improvements, etc. Focus should remain on achieving specific environmental and social improvements to the product profile, while realizing results achieved throughout the improvement process.

During this and subsequent stages, the organization can begin (or continue) to broaden its relationship in the product chain. It is much easier to develop a base of knowledge if there is cooperation and an atmosphere of trust among producers, suppliers, retail store owners, disposal facilities and other stakeholders in the product chain.

\section{Concluding Remarks}

With a number of drivers both from governments, consumers, social activists, suppliers of technological advancement, internal CSR strategies and so on, companies are becoming more engaged in sustainability practices. LCM is an approach to help companies set up Life Cycle Management initiatives, to achieve environmental, economic and social benefits at the same time through implementing a step-by-step quality management tool. The relevance of the PDCA cycle is discussed to ensure a continuous performance improvement by setting and implementing a well-defined plan, checking whether the ambition goals and targets are achieved or any adjustment actions are needed as part of the evaluation process.

LCM has been identified as the way to operationalize sustainability challenges into business practices; however, its implementation faces significant challenges. Setting clear and measureable goals is one of the challenges. The focus of LCM initiatives is different from the usual business strategies, which are mainly focusing on maximizing the profit as the ultimate goal. LCM initiatives have a wider scope in order to have both social and environmental benefits along with maintaining the economic advantages. The divergent priorities between the financial and sustainability focuses are challenging tasks for managers at different organizational level. A successful implementation of LCM then needs a full integration across the organization.

Another challenge to implementing LCM into business practices is when there is a cost associated with the suggested improvements. In some cases, the economic benefits of being sustainable are seen in short-term actions. This is the case, when initiatives significantly reduce the energy and resource consumption, which internally provide financial benefits to the company. Such initiatives are easy to implement as they provide the company with environmental, social and economic benefits simultaneously. But this is not always true. In some cases, sustainability actions 
come with costs and fail to provide short-term financial incentives. Companies need to perceive the long-term positive consequence of their sustainability endearment, which can improve their attractiveness to consumer and increase their competitiveness in the long run.

Open Access This chapter is distributed under the terms of the Creative Commons Attribution Noncommercial License, which permits any noncommercial use, distribution, and reproduction in any medium, provided the original author(s) and source are credited.

\section{References}

3M (2014) Innovation improving lives - sustainability report

BASF (2015) Sustainability. https://www.basf.com/en/company/sustainability/management-andinstruments/our-goals.html. Accessed 10 Mar 2015

Carraro C, Galeotti M (1997) Economic growth, international competitiveness and environmental protection: R\&D nd innovation strategies with WARM model. Energy Econ 19:2-28

Cherian J, Jacob J (2012) Green marketing: a study of consumers' attitude towards environment friendly products. Asian Soc Sci. doi:10.5539/ass.v8n12p117

Deming WE (1952) Elementary principles of the statistical control of quality: a series of lectures, 2nd edn. Nippon Kagaku Gijutsu Remmei, Tokyo, 103

Dinda S (2004) Environmental Kuznets curve hypothesis: a survey. Ecol Econ 49:431-455. doi:10.1016/j.ecolecon.2004.02.011

EC (2011) A renewed EU strategy 2011-14 for corporate social responsibility. European Commission, Brussels

EC (2014) Directive 2014/95/EU of the European Parliament and the Council - amending Directive 2013/34/EU as regards disclosure of non-financial and diversity information by certain large undertakings and groups

Estein M, Buhovac A (2010) Solving the sustainability implementation challenge. Organ Dyn 39:306-315

Finkbeiner M (2011) Towards life cycle sustainability management. Springer, Dordrecht/ Heidelberg/London/New York

Ginsburg JM, Bloom PN (2004) Choosing the right green marketing strategy. MIT Sloan Manag Rev 46:79-84

GRI (2013) G4 sustainability reporting guidelines: reporting principles and standard disclosures

ISO (2004) ISO 14001:2004 Environmental management systems - requirements with guidance for use

ISO (2008) ISO 9001:2008 Quality management systems

ISO (2013) ISO 14031:2013 -Environmental management - environmental performance evaluation - guidelines

Labuschagne C, Brent AC, van Erck RPG (2005) Assessing the sustainability performances of industries. J Clean Prod 13:373-385. doi:10.1016/j.jclepro.2003.10.007

Lacy P, Cooper T, Hayward R, Neuberger L (2010) A new era of sustainability. UN global compactaccenture CEO study 2010. Routledge, London

McDonough EF III (2000) Investigation of factors contributing to the success of cross-functional teams. J Prod Innov Manage 17:221-235. doi:10.1016/S0737-6782(00)00041-2

McWilliams A, Siegel D (2001) Corporate social responsibility: a theory of the firm perspective. Acad Manage Rev 26:117-127. doi:10.2307/259398

Moen R, Norman C (2006) Evolution of the PDCA cycle. Accessed 1 Feb 2015. http://pkpinc.com/ files/NA01MoenNormanFullpaper.pdf 
Perrini F, Castaldo S, Misani N, Tencati A (2010) The impact of corporate social responsibility associations on trust in organic products marketed by mainstream retailers: a study of Italian consumers. Bus Stratege Environ 19:512-526. doi:10.1002/bse.660

Porter ME, Kramer MR (2006) Strategy and society: the link between competitive advantage and corporate social responsibility. Harvard Bus Rev 84:78-92

Remmen A, Jensen AA, Frydendal J (2007) Life cycle management. A business guide to sustainability. UNEP/SETAC Life Cycle Initiative

Shewhart WA (2011) Statistical method from the viewpoint of quality control. Dover Publications

Simpson M, Taylor N, Barker K (2004) Environmental responsibility in SMEs: does it deliver competitive advantage? Bus Stratege Environ 13:156-171

Sokovic M, Pavletic D, Kern Pipan K (2010) Quality improvement methodologies - PDCA cycle, RADAR matrix, DMAIC and DFSS. J Achiev Mater Manufacturing Eng 43/1, Nov. 2010

SONY (2015) Towards zero carbon emissions. http://www.sony.co.uk/hub/eco/sustainablebusiness-processes/zero-emissions

UNEP (2011) Towards a life cycle sustainability assessment: making informed choices on products. UNEP/SETAC, Paris

UNEP/SETAC (2013) LCM training material. http://www.lifecycleinitiative.org/resources/training/. Accessed 7 Feb 2015 